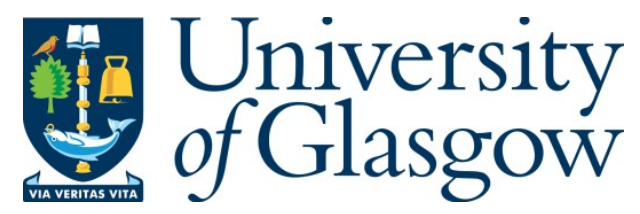

Young, G., Karimi, N. and Mackenzie, R. (2020) Numerical modelling of subcooled flow boiling and heat transfer enhancement: validation and applicability to fusion reactor target design. Journal of Energy Resources Technology, 142(11), 112105.

(doi: $\underline{10.1115 / 1.4047254)}$

There may be differences between this version and the published version. You are advised to consult the publisher's version if you wish to cite from it.

http://eprints.gla.ac.uk/212286/

Deposited on: 16 March 2020

Enlighten - Research publications by members of the University of Glasgow http://eprints.gla.ac.uk 


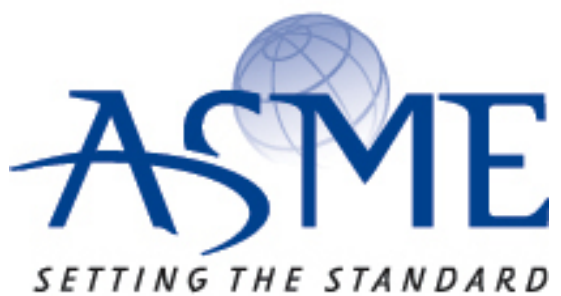

SETTING THE STANDARD

\section{American Society of Mechanical Engineers}

ASME Accepted Manuscript Repository

Institutional Repository Cover Sheet

First

Last

ASME Paper Numerical modelling of subcooled flow boiling and heat transfer enhancement:

Title: $\quad$ validation and applicability to fusion reactor target design

Authors: $\quad$ Graeme Young, Nader Karimi, Ross Mackenzie

ASME Journal

Title:

Journal of Energy Resources Technology

Volume/Issue

Date of Publication (VOR* Online)

142(11)

June 9, 2020

ASME Digital Collection https://asmedigitalcollection.asme.org/energyresources/article-

URL:

abstract/142/11/112105/1083931/

DOI: $\quad \underline{\underline{10.1115 / 1.4047254}}$ 


\title{
NUMERICAL MODELLING OF SUBCOOLED FLOW BOILING AND HEAT TRANSFER ENHANCEMENT: VALIDATION AND APPLICABILITY TO FUSION REACTOR TARGET DESIGN
}

\author{
Graeme Young ${ }^{1}$, Nader Karimi ${ }^{1,2}$, Ross Mackenzie ${ }^{3}$, \\ 1James Watt School of Engineering, University of Glasgow, Glasgow G12 8QQ, UK \\ ${ }^{2}$ School of Engineering and Materials Science, Queen Mary University of London, London E1 4NS, \\ UK \\ ${ }^{3}$ Mott MacDonald Ltd., St Vincent Plaza, 319 St Vincent St, Glasgow G2 5LD, UK
}

\section{ABSTRACT}

Boiling flows are an extremely efficient mechanism for the transfer of ultra-high heat fluxes and used in numerous industrial applications. In this paper, the accuracy of computational fluid dynamics in predicting the temperature distributions and heat transfer performance is examined within a nuclear fusion reactor divertor. The aim is to establish the role of CFD within the design of complicated high heat flux components using a semi-mechanistic approach to flow boiling that is independent of geometry and flow conditions. An Eulerian-Eulerian two-fluid method is developed and a conjugate heat transfer model is validated against the existing experimental data where available. Overall, a satisfactory accuracy is achieved in the prediction of several important quantities. Temperature distribution throughout the divertor is found to be highly accurate and aligns with the physical testing across two expected operating regimes. Additionally, the system heat transfer coefficients and coolant temperatures are close to the assumptions already established within the literature. Heat transfer enhancement is a critical component of the divertor design and a twisted tape insert appears to be necessary for the system to withstand ultra-high heat fluxes encountered within the fusion reactor. The results show that inclusion of a twisted tape improved the heat transfer coefficient of the system by almost
$45 \%$ allowing the divertor to withstand the required heat fluxes of $10 \mathrm{MW} / \mathrm{m}^{2}$ and $20 \mathrm{MW} / \mathrm{m}^{2}$.

Keywords: forced convection boiling, multiphase flow modelling, ITER, twisted tape, nuclear fusion reactor, divertor.

\section{NOMENCLATURE}

$C_{D} \quad$ drag coefficient

$C_{p} \quad$ specific heat capacity, $\mathrm{J} \mathrm{kg}^{-1} \mathrm{~K}^{-1}$

$\widehat{\boldsymbol{E}}_{k}^{i} \quad$ interfacial heat transfer rate

G mass flux, $\mathrm{kg} \mathrm{m}^{-2} \mathrm{~s}^{-1}$

$H \quad$ length for $180^{\circ}$ of twist

I identity matrix

$K_{d r y} \quad$ fraction of heated wall in contact with vapour

$\widehat{\boldsymbol{M}}_{k}^{i} \quad$ interfacial force

$P_{f} \quad$ fluid pressure, $\mathrm{Pa}$

$P_{\text {sys }} \quad$ system pressure, $\mathrm{MPa}$

$R \quad$ specific gas constant, $\mathrm{J} \mathrm{kg}^{-1} \mathrm{~K}^{-1}$

$R_{c} \quad$ critical cavity radius, $\mathrm{m}$

$T_{0} \quad$ specific time-scale

$T_{l} \quad$ near-wall liquid temperature, $\mathrm{K}$

$T_{w} \quad$ wall temperature, $\mathrm{K}$

$T R \quad(\mathrm{H} / \mathrm{d})$ twist ratio

$d \quad$ diameter, $\mathrm{m}$ 


$\begin{array}{ll}d_{b} & \text { bubble diameter, } \mathrm{m} \\ d_{w} & \text { bubble departure diameter, } \mathrm{m} \\ \boldsymbol{e} & \text { specific internal energy } \\ f & \text { bubble departure frequency, } \mathrm{s}^{-1} \\ f_{2} & \text { damping function } \\ f\left(\rho^{+}\right) & \text {non-dimensional logarithmic density function } \\ \boldsymbol{g} & \text { gravitational acceleration, } \mathrm{m} \mathrm{s}^{-2} \\ h_{l g} & \text { latent heat of vaporisation, } \mathrm{J} \mathrm{kg}^{-1} \\ h_{Q} & \text { quenching heat transfer coefficient } \\ k & \text { turbulent kinetic energy, } \mathrm{m}^{2} \mathrm{~s}^{-2} \\ n^{\prime \prime} & \text { nucleation site density, } \mathrm{m}^{-2} \\ \bar{n}^{\prime \prime} & \text { average cavity density, } \mathrm{m}^{-2} \\ p & \text { pressure, Pa } \\ q & \text { heat flux, } \mathrm{W} \text { m } \\ \dot{q}_{e}^{\prime \prime} & \text { evaporative heat flux, } \mathrm{W} \mathrm{m}^{-2} \\ \dot{q}_{l \varnothing}^{\prime \prime} & \text { liquid phase heat flux, } \mathrm{W} \mathrm{m}^{-2} \\ \dot{q}_{v}^{\prime \prime} & \text { vapour phase heat flux, } \mathrm{W} \mathrm{m}^{-2} \\ \dot{q}_{w}^{\prime \prime} & \text { total wall heat flux, } \mathrm{W} \mathrm{\textrm {m } ^ { - 2 }} \\ \dot{q}_{Q}^{\prime \prime} & \text { quenching heat flux, } \mathrm{W} \mathrm{\textrm {m } ^ { - 2 }} \\ t & \text { time, } \mathrm{s} \\ t_{w} & \text { bubble wait time, } \mathrm{s} \\ t^{+} & \text {non-dimensional temperature } \\ u_{k} & \text { internal energy, } \mathrm{m}^{2} \mathrm{~kg} / \mathrm{s}^{2} \\ u_{l}^{*} & \text { liquid phase velocity, } \mathrm{ms}^{-1} \\ u_{v}^{*} & \text { vapour phase velocity, } \mathrm{ms}^{-1} \\ v_{k} & \text { velocity, ms }{ }^{-1} \\ y^{+} & \text {non-dimensional wall height } \\ & \end{array}$

\section{Greek Letters}

$\alpha \quad$ volume fraction

$\Gamma \quad$ net mass transfer rate

$\Delta T_{\text {sub }} \quad\left(T_{\text {sat }}-T_{l}\right)$ liquid subcooling, $\mathrm{K}$

$\Delta \rho \quad$ density difference, $\mathrm{kg} \mathrm{m}^{-3}$

$\varepsilon \quad$ turbulent dissipation energy

$\theta \quad$ wall contact angle, rad

$\lambda \quad$ thermal conductivity, $\mathrm{W} \mathrm{m}^{-1} \mathrm{~K}^{-1}$

$\lambda^{\prime} \quad$ cavity length scale

$$
\begin{array}{ll}
\mu & \text { dynamic viscosity, Pa s } \\
\mu_{c a} & \text { contact angle, rad } \\
\mu_{t} & \text { turbulent eddy viscosity, Pa s } \\
\hat{\mu} & \text { total interfacial force per unit volume } \\
\rho & \text { density, } \mathrm{kg} \mathrm{m}^{-3} \\
\rho^{+} & \text {non-dimensional density difference } \\
\rho^{*} & \text { non-dimensional density difference } \\
\boldsymbol{\tau}^{\text {tot }} & \text { total shear stress }
\end{array}
$$

\section{Subscripts and Superscripts}

$\begin{array}{ll}\text { in } & \text { inlet } \\ l & \text { liquid } \\ \text { out } & \text { outlet } \\ \text { sat } & \text { saturation } \\ v & \text { vapour } \\ w & \text { wall }\end{array}$

\section{Non-Dimensional Numbers}

$\begin{array}{ll}E o & \text { Eötvös number } \\ P r & \text { Prandtl number } \\ R e & \text { Reynolds number }\end{array}$

\section{INTRODUCTION}

Nuclear fusion has long been favoured as the future of clean and sustainable energy, however, the endeavour is accompanied with significant engineering and design challenges [1]. World energy consumption has doubled since 1973 and is forecast to more than double again by the mid-century [2,3]. ITER, meaning 'the way' in Latin, is an experimental thermonuclear fusion reactor that is currently the largest and most expensive foray into fusion energy generation and one of the most expensive nuclear energy investments worldwide [4,5]. The project intends to answer the challenging questions that loom over successful commercial fusion energy. The immense international project aims to be the first reactor with a net generation of power, obtaining an output/input energy ratio $(\mathrm{Q}$ value) of 10 for a 50MW energy input [5]. The ITER reactor is a 23,000 tonne tokamak fusion reactor that will contain a plasma volume of $830 \mathrm{~m}^{3}[5,6]$ A stainless-steel vacuum vessel forms the 
skeleton which houses the two plasma facing components of the tokamak: the first wall and the divertor. These units are expected to protect the complex while acting as a heat exchanger where the energy can be converted to electricity through the Rankine or Brayton cycles. These components are exposed to the heat fluxes generated by the plasma which is held at 150 million degrees Celsius [7]. A cutaway diagram of the full tokamak reactor complex is presented in Figure 1 [8].

Flow boiling is used in a multitude of engineering applications where efficient delivery of intense thermal loading is required to protect mission critical components. The $500 \mathrm{MW}$ ITER fusion reactor is no exception, expected to withstand some of the largest heat fluxes in modern engineering. Situated at the base of the ITER tokamak reactor is the divertor, a component that maintains direct plasma contact and is exposed to the highest heat fluxes within the reactor during operation. Acting as a neutron shield for the superconducting magnets and vacuum vessel while filtering out impurities through plasma-wall interactions, divertor functionality is crucial to the success of ITER [9]. The integrity of the water-cooled divertor is maintained through the use of subcooled flow boiling, a complicated phenomenon that is often utilized in the nuclear industry and is typically used to cool fuel rods [10].

Divertor design is a complicated process given the high temperatures and challenging fluid dynamics which arise from the unique geometry and hydrodynamic phenomena in flow boiling. These constraints limit the capability of lookup tables, correlations and simplistic 1D codes that must be tuned to specific scenarios on a case-by-case basis. Mohanty and Das [11] in their review of boiling correlations found that some may be off by as much as $60 \%$ when used on different sets of experimental data. Computational fluid dynamics (CFD) offers the ability to address design concerns with models not limited to specific geometries while providing a greater insight into the thermodynamic performance of the divertor and forced convection boiling.
The ITER divertor is comprised of 54 divertor cassettes located at the base of the vacuum vessel, each roughly $3.5 \mathrm{~m}$ across, containing three plasma-facing units (PFUs): an inner vertical target (IVT), outer vertical target (OVT) and dome [12]. The divertor may be seen at the base of the tokamak complex in Figure 1. Both vertical targets are constructed in two halves from a series of channels lined with 144 tungsten or carbon-fibre composite monoblocks. Design is varied, with the IVT having 16 coolant channels while the OVT has 22, many of which are shaped and chamfered to reduce thermal loads from off-normal plasma contact [12-14]. The IVT and OVT are both fitted with passive heat transfer enhancement in the form of copper swirl tapes in the lower, higher heat flux handling regions.

This study uses the design specifications for a fully tungsten divertor to model an ITER-like single channel from a water-cooled IVT without roof shaping on the plasma-facing monoblock surfaces. Contemporary designs for tokamak targets such as those in the upcoming DEMO reactor are similarly based on the ITER design philosophy and its wealth of research data. The structure of the single-channel is formed by a $\mathrm{CuCrZr}$ pipe which is bonded to the plasma-facing tungsten blocks via a thin $\mathrm{Cu}$ interlayer [15]. Tungsten is currently regarded as the most suitable PFU material given its refractory thermophysical properties and low propensity to sputter. The IVT and OVT are expected to operate at steady-state loads of $10 \mathrm{MW} / \mathrm{m}^{2}$ and slowtransient loads of $20 \mathrm{MW} / \mathrm{m}^{2}$ for a maximum of ten seconds. Such loads produce surface temperatures exceeding $1000^{\circ} \mathrm{C}$ and $2000^{\circ} \mathrm{C}$ respectively [15-17].

Subcooled flow boiling or forced convection boiling is used for its ability to deliver high rates of heat transfer in compact spaces and with limited wall superheat [18-20]. In ITER, however, highly subcooled boiling is utilised, where the fluid core is expected to remain $100^{\circ} \mathrm{C}$ below saturation temperature [21]. As the coolant is brought to saturation temperature, bubbles, typically less than a millimetre in diameter, form along the channel walls. Once large enough, bubbles are lifted from the channel wall and condense in the 
subcooled liquid core within fractions of a second, depositing their energy into the water [22]. While the capabilities of flow boiling are widely utilised, the mechanisms that underpin the processes in nucleate boiling are still not wholly understood [11,23-25]. The flow conditions within the divertor are further complicated by the inclusion of swirl-inducing twisted tape and non-uniform, single-sided heat flux from the divertor plates. The upward flow in the vertical divertor results in a flow regime characterised by a bubbly flow given the high liquid fraction [26]. These factors are important as they have a dramatic influence over the bubble hydrodynamics which is critical to the accurate determination of heat transfer coefficients and temperature profiles. Thus, it is important that any CFD model accurately captures nucleation site density, bubble departure frequency, bubble departure diameter and bubble hydrodynamics. These further highlight the utility in CFD models which can model the highly specialized design of the divertor and reduce the expense required for physical testing.

Recently, a common approach to tackling multiphase flows and flow boiling is the use of the Eulerian-Eulerian twofluid model which has seen successes in predicting void fraction, temperature, velocity profiles and chemical reactions $[19,26,27]$. In Eulerian multiphase conjugate heat transfer both phases are treated as separate interpenetrating continua as a set of averaged conservation equations where momentum, energy and continuity equations are solved separately for each phase [28,29]. Detailed discussion of these models may be found in [10] and [30]. Details are lost in the averaging process and additional closure models are required for the interfacial mass, energy and momentum transfers $[27,31,32]$. However, despite the rapid growth of CFD in the last decade, analysis of boiling flows and accurate heat transfer between solid and two-phase flows is still challenging and much is still to be done in the analysis of complex 3D geometry. One problem is the lack of varied experimental data for flow boiling which is limited to the averaged axial void profiles and wall temperatures produced by Bartolomei and Chanturiya and Bartolomei et al. for upward water flow boiling in pipes at high pressures and moderate heat fluxes [33,34]. Currently there are a number of models that are used in the twofluid model, those being Lemmert-Chawla [35] and Hibiki-Ishii [36] for active nucleation site density, Cole [37] for the departure frequency, and Tolubinsky-Konstanchuk [38] and Kocamustafaogulari [39] for bubble departure diameter. Colombo and Fairweather in their analysis of the current models found that there were still improvements to be made in relation to modelling of bubble departure diameter, bubble coalescence and the near-wall turbulence modelling. Elsewhere, Langari et al. [19], Yun et al. [40] and Končar and Tiselj [41] demonstrated that the selection of turbulence model and near wall velocity profile can substantially affect the wall temperatures in boiling flows. It is clear that the two-fluid model is capable of accurate modelling of boiling flows in simple circular cross-section tubes under high and uniform heat fluxes and merits investigation of applicability to divertor design.

Twisted tape serves as a passive heat transfer enhancement device that Bergles [42] finds to be the most simple and effective method of doing so. Twisted tapes are typically defined by their dimensionless twist ratio (TR). Its inclusion in the design directly influences the thermodynamic phenomena in two-phase flows. With turbulent flows, the tapes have less influence on the already well mixed flow, however, in the subcooled regime the tape increases the critical heat flux (CHF) and prevents burnout by always ensuring there is fluid along the walls. Manglik and Bergles [43] found that the process of boiling is the same for flows with twists as with straight flows. Currently there are only a few studies performing conjugate heat transfer CFD on the effects of twisted-tape inserts on subcooled flows under extremely high heat fluxes $[44,45]$. Hence, there is a need for further study of these problems and this paper aims to respond to this issue. 


\section{MATHEMATICAL MODELS AND NUMERICAL METHODS}

In this paper, the Eulerian-Eulerian two-fluid model is employed in STAR-CCM+13.02 [46] to assess the capability of the two-fluid model in predicting temperature distributions and the effects of passive heat transfer enhancement. This is undertaken by running a full-scale 3D conjugate heat transfer study on a single channel from the divertor with the inclusion of twisted tape under ITER operational loads. Maximum surface temperatures are compared against ITER mechanical testing before changes are made to the twisted tape to investigate the heat transfer performance and vapour generation with the current models.

Subcooled boiling occurs at the heated wall surface when heat flux at the boundary is too high to be removed via singlephase conductive-convective heat transfer. The term "subcooled" indicates that only the local wall flow has exceeded boiling point while the remainder of the bulk flow is below saturation temperature. Along the channel bubbles of steam form at nucleation sites, the density of which is determined by the flow conditions and wall superheat. These bubbles grow downstream and detach from the surface once they reach the critical diameter. The critical diameter is influenced by the local flow conditions and surface tension.

The standard two-fluid ensemble-averaged conservation equations may be written as follows:

The conservation of mass reads:

$$
\frac{\partial\left(\alpha_{k} \rho_{k}\right)}{\partial t}=\nabla \cdot\left(\alpha_{k} \rho_{k} v_{k}\right)=\Gamma_{k}
$$

The conservation of momentum is written as:

$$
\begin{aligned}
\frac{\partial\left(\alpha_{k} \rho_{k} \boldsymbol{v}_{k}\right)}{\partial t}+\nabla \cdot & \left(\alpha_{k} \rho_{k} \boldsymbol{v}_{k} \boldsymbol{v}_{k}\right) \\
& =-\nabla\left(\alpha_{k} p_{k}\right)+\nabla \cdot\left(\alpha_{k} \boldsymbol{\tau}_{k}^{t o t}\right)+\alpha_{k} \rho_{k} \boldsymbol{g} \\
& +\widehat{\boldsymbol{M}}_{k}^{i}
\end{aligned}
$$

and the conservation of energy is governed by:

$$
\begin{gathered}
\frac{\partial\left(\alpha_{k} \rho_{k} \boldsymbol{e}_{k}\right)}{\partial t}+\nabla \cdot\left(\alpha_{k} \rho_{k} \boldsymbol{v}_{k} \boldsymbol{e}_{k}\right)=-\nabla\left(\alpha_{k} q_{k}^{t o t}\right)+\nabla \cdot\left(\alpha_{k} \boldsymbol{\tau}_{k}^{t o t}\right)+ \\
\nabla \cdot\left[\alpha_{k}\left(-p_{k} \boldsymbol{I}+\boldsymbol{\tau}_{k}^{t o t}\right) \cdot \boldsymbol{u}_{k}\right]+\alpha_{k} \rho_{k} \boldsymbol{g} \cdot \boldsymbol{u}_{k}+\widehat{\boldsymbol{E}}_{k}^{i}
\end{gathered}
$$

where $\boldsymbol{v}_{k}, \boldsymbol{e}_{\boldsymbol{k}}, \rho_{k}$ and $\alpha_{k}$ are velocity, specific internal energy, density and volume fraction respectively. The term $\Gamma_{k}$ is the net mass transfer rate where $\boldsymbol{\tau}_{k}^{\text {tot }}$ is total shear stress, $\boldsymbol{g}$ is the gravity vector, $q_{k}^{\text {tot }}$ is the total heat flux, $\widehat{M}_{k}^{i}$ is total interfacial force per unit volume and $\widehat{\boldsymbol{E}}_{k}^{i}$ is interfacial heat transfer rate all for field-k. Further information on the details of the governing equations can be found in references [10] and [47].

The turbulent heat flux equation accounts for both turbulent energy convection and turbulent work and is represented by the following [10]:

$$
\boldsymbol{q}_{k}^{T}=\overline{\overline{\rho_{k}\left(u_{k}+\frac{v_{k}^{2}}{2}\right)^{\prime} \boldsymbol{v}_{k}^{\prime}}}-\overline{\overline{\overline{\tau_{k} \cdot \boldsymbol{v}_{k}^{\prime}}}}+\overline{\overline{\overline{p_{k} \cdot \boldsymbol{v}_{k}^{\prime}}}}
$$

A Two-Layer Realizable $k-\varepsilon$ model is used over the standard model for its improved ability to capture rotational flow, strong adverse pressure gradients and boundary layers which are of particular importance within the divertor channel flow [48]. A new equation for the turbulent dissipation, $\varepsilon$, is used, while a new coefficient $C_{\mu}$ is introduced as a function of the mean flow and turbulence properties rather than a constant in the standard $k-\varepsilon$ model. The formulation of the turbulence model is the same for each phase as it is in single-phase flows, however, each phase is scaled with a factor of the phase volume fraction. The transport equation for kinetic energy $k$ is given by the following equation:

$$
\begin{aligned}
\frac{\partial}{\partial t}(\rho k)+\nabla \cdot(\rho k & \bar{v}) \\
& =\nabla \cdot\left[\left(\mu+\frac{\mu_{t}}{\sigma_{k}}\right) \nabla k\right]+P_{k}-\rho\left(\varepsilon-\varepsilon_{0}\right) \\
& +S_{k}
\end{aligned}
$$

and turbulent dissipation rate, $\varepsilon$, is given by:

$$
\begin{aligned}
\frac{\partial}{\partial t}(\rho k)+\nabla \cdot(\rho \varepsilon \overline{\boldsymbol{v}}) & \\
= & \nabla \cdot\left[\left(\mu+\frac{\mu_{t}}{\sigma_{\epsilon}}\right) \nabla \varepsilon\right]+\frac{1}{T_{e}} C_{\varepsilon 1} P_{\varepsilon} \\
& -C_{\varepsilon 2} f_{2}\left(\frac{\varepsilon}{\mathrm{T}_{\mathrm{e}}}-\frac{\varepsilon_{0}}{\mathrm{~T}_{0}}\right)+S_{\varepsilon}
\end{aligned}
$$

where $\bar{v}$ is the mean velocity, $\mu$ is dynamic viscosity, $\sigma_{k}, \sigma_{\varepsilon}, C_{\varepsilon 1}$ and $C_{\varepsilon 2}$ are the model coefficients. $P_{k}$ and $P_{\varepsilon}$ are production 
terms, $f_{2}$ is a damping function and $S_{k}$ and $S_{\varepsilon}$ are user-specified source terms [46].

Specific time-scale is defined by:

$$
T_{0}=\max \left(\frac{k_{0}}{\varepsilon_{0}}, C_{t} \sqrt{\frac{v}{\varepsilon_{0}}}\right)
$$

In the RPI model provided by Kurul and Powdowski [49] the total wall heat flux $\left(\dot{q}_{w}^{\prime \prime}\right)$ is characterized by three different modes of heat transfer; single-phase convection $\left(\dot{q}_{l \varnothing}^{\prime \prime}\right)$, transient conduction $\left(\dot{q}_{Q}^{\prime \prime}\right)$ and evaporation $\left(\dot{q}_{e}^{\prime \prime}\right)$. Thus, the total sum at the wall is expressed as the sum of the three fluxes and a vapour contribution $\left(\dot{q}_{v}^{\prime \prime}\right)$ as:

$$
\dot{q}_{w}^{\prime \prime}=\left(\dot{q}_{l ø}^{\prime \prime}+\dot{q}_{e}^{\prime \prime}+\dot{q}_{Q}^{\prime \prime}\right)\left(1-K_{d r y}\right)+K_{d r y} \dot{q}_{v}^{\prime \prime}
$$

The convective heat flux contribution assumes the removal of heat flux using single-phase turbulent heat transfer. For liquid in wall-contact the following equation is used:

$$
\dot{q}_{l \varnothing}^{\prime \prime}=\frac{\rho_{l} c_{p, l} u_{l}^{*}}{t_{l}^{+}}\left(T_{w}-T_{l}\right)
$$

The vapour convection contribution at the wall is given by:

$$
\dot{q}_{v}^{\prime \prime}=\frac{\rho_{v} c_{p, v} u_{v}^{*}}{t_{v}^{+}}\left(T_{w}-T_{v}\right)
$$

Evaporative heat flux is given by:

$$
\dot{q}_{e}^{\prime \prime}=n^{\prime \prime} f\left(\frac{\pi d_{w}^{3}}{6}\right) \rho_{v} h_{l g}
$$

where $f$ is the bubble departure frequency, $n^{\prime \prime}$ is number of nucleation sites per unit area, $d_{w}$ is the bubble departure diameter and $h_{l g}$ is the latent heat of vaporization.

Quenching heat flux is modelled using the Del Valle and Kenning [50] analytical model and describes the heat flux used in heating the liquid that fills the space that was previously occupied by the departing bubble.

$$
\dot{q}_{Q}^{\prime \prime}=2 K^{\prime \prime} f \sqrt{\frac{\rho_{l} C_{p, l} \lambda_{l} t_{w}}{\pi}} \frac{T^{+}\left(y_{Q}\right)}{T^{+}\left(y_{c}\right)}\left(T_{w}-T_{l}\right)
$$

where $T^{+}(y)$ is the dimensionless temperature profile, $y_{c}$ is the distance from the wall to nearest cell centre and $y_{Q}$ is the distance from the wall at which liquid is drawn in after bubble departure. The area affected by evaporation is represented by:

$$
K^{\prime \prime}=2 \frac{\pi d_{w}^{2}}{4} n^{\prime \prime}
$$

The waiting time, $t_{w}$, is the time between detachment of a bubble and nucleation of another:

$$
t_{w}=\frac{0.8}{f}
$$

Additional models which are required in order to close the boiling model are the following:

Bubble Departure Diameter Model

In general bubble departure diameter models take the general form [51]:

$$
d_{b}=d_{b, 0}\left(T_{w}-T_{s a t}\right)^{m}
$$

where $\mathrm{m}=0$ and $d_{b, 0}$ is a function of the thermal properties, liquid subcooling, bubble contact angle and wall surface material and is calculated using the following Tolubinsky-Konstanchuk correlation [38]:

$$
\min \left[0.6 m m \exp \left(-\Delta T_{\text {sub }} / 45 \mathrm{~K}\right), 0.0014\right]
$$

(ii) Nucleation Site Density Model

Nucleation site density equations are expressed by the HibikiIshii [36] model using the following relation

$$
n^{\prime \prime}=\overline{n^{\prime \prime}}\left\{1-\exp \left(-\frac{\theta^{2}}{8 \mu_{c a}^{2}}\right)\right\}\left[\exp \left\{f\left(\rho^{+}\right) \frac{\lambda^{\prime}}{R_{c}}\right\}-1\right]
$$

where $\overline{n^{\prime \prime}}=4.75 \times 10^{5}$ sites $/ \mathrm{m}^{2}, \theta=0.722 \mathrm{rad}$,

$\mu_{c a}=0.722 \mathrm{rad}, \lambda^{\prime}=2.5 \times 10^{-6} \mathrm{~m}$,

and the critical cavity radius is given by:

$$
R_{c}=\frac{2 \sigma\left\{1+\left(\rho_{v} / \rho_{1}\right)\right\} / P_{f}}{\exp \left\{h_{l v}\left(T_{v}-T_{\text {sat }}\right) /\left(R T_{v} T_{\text {sat }}\right)\right\}-1}
$$

where:

$$
\begin{gathered}
f\left(\rho^{+}\right)=-0.01064+0.48246 \rho^{+}-0.22712 \rho^{+2} \\
+0.05468 \rho^{+3},
\end{gathered}
$$

$\rho^{+}=\log \left(\rho^{*}\right), \mathrm{R}$ is the gas constant based on molecular weight and:

$$
\rho^{*}=\left(\rho_{1}-\rho_{v}\right) / \rho_{v}
$$

(iii)

\section{Bubble Departure Frequency}

For departure frequency Cole's [52] model is used: 


$$
f=\sqrt{\frac{4 g\left(\rho_{1}-\rho_{v}\right)}{3 d_{b} \rho_{l}}}
$$

Finally, the interfacial continuous phase Nusselt number used to determine the heat transfer from the bulk water to the bubble interface is calculated by the Ranz-Marshall [53] correlation:

$$
h_{l}=\frac{\lambda_{l}}{d_{b}}\left(2+0.6 \operatorname{Re}^{1 / 2} \operatorname{Pr}^{1 / 3}\right)
$$

Drag coefficient is calculated using the Tomiyama et al. [54] drag coefficient for bubbles in its pure form with no surfactants:

$C_{D}=\max \left[\min \left(\frac{16}{R e}\left(1+0.15 R e^{0.687}, \frac{48}{R e}\right), \frac{8 E o}{3(E o+4)}\right)\right]$

where:

$$
R e=\frac{\rho_{1}\left|v_{r}\right| d_{b}}{\mu_{1}}
$$

and:

$$
E o=\frac{\left|\rho_{1}-\rho_{\mathrm{g}}\right| g d_{b}{ }^{2}}{\sigma}
$$

\section{BOILING MODEL VALIDATION}

The most suitable experimental data set for the evaluation of the boiling models are those conducted by Bartolomei and Chanturiya [33] and Bartolomei et al. [34]. This arrangement represents the high-pressure system and subcooled boiling found within ITER. This experiment is simple to reproduce and shares the same upward flow conditions. Availability of high heat flux subcooled flow boiling for twisted tapes was unavailable during the CFD testing. Performance for the final model is evaluated on its ability to predict temperature distributions throughout the divertor when compared with ITER two-colour pyrometer physical testing temperature data and finite element analysis simulation [55].

A two-dimensional axisymmetric model was used to validate the performance of the boiling model developed in this paper. The data was compared against the experiments by Bartolomei [33]. A $2000 \mathrm{~mm}$ long, $15.4 \mathrm{~mm}$ wide pipe is heated uniformly along its length with a heat flux of $0.57 \mathrm{MW} / \mathrm{m}^{2}, \mathrm{~T}_{\mathrm{i}}=$ $470 \mathrm{~K}, \mathrm{G}=900 \mathrm{~kg} / \mathrm{m}^{2} \mathrm{~s}$ and $\mathrm{P}_{\text {sys }}=4.5 \mathrm{MPa}$ with inlet $\Delta \mathrm{T}_{\text {sub }}=$ $58.2 K$.
Figure 3 shows a comparison between the current simulation and the experimental data of Bartolomei [33]. Evidently, the models selected in this paper show good agreement with the experimental data for the flow conditions modelled. Figure $3 \mathrm{a}$ shows the wall superheat prediction is highly accurate, however, Figure $3 \mathrm{~b}$ indicated an overprediction of axial subcooling at low thermodynamic qualities due to the initial overprediction of wall superheat. In Fig $3 a$ it is also clear that the experimental setup has had some heating ahead of the heated section within the experiment. Additionally, the flow solver takes time to fully create the thermodynamic boundary layer and thus underpredicted wall superheat quite consistently. However, after that point, the wall superheat temperatures were within $8 \%$ to $20 \%$ of those obtained experimentally. Figure 4 a shows a clear overprediction at very low thermodynamic qualities which may be attributed to the overpredicted wall superheat, however, at moderate qualities the vapour generation is in close agreement with the experimental data and consistent with the more accurate wall superheat.

\section{ITER MODEL CONFIGURATION}

A three-dimensional steady-state two-fluid model is used to represent the ITER single-channel configuration during both steady-state and transient heating thermal loading. The inlet conditions and system characteristics can be found in Table 1 .

\begin{tabular}{|c|c|c|}
\hline Heat Flux & Low $\left(10 \mathrm{MW} / \mathrm{m}^{2}\right)$ & High $\left(20 \mathrm{MW} / \mathrm{m}^{2}\right)$ \\
\hline Tsat $(\mathrm{K})$ & 530 & 530 \\
\hline Psys $(\mathrm{MPa})$ & 4.0 & 4.0 \\
\hline Vin $(\mathrm{m} / \mathrm{s})$ & 9.0 & 9.0 \\
\hline Tin $(\mathrm{K})$ & 373 & 373 \\
\hline Gin $\left(\mathrm{kg} / \mathrm{m}^{2} \mathrm{~s}\right)$ & 8628 & 8628 \\
\hline UVT $\left(\mathrm{MW} / \mathrm{m}^{2}\right)$ & 5 & 5 \\
\hline LVT $\left(\mathrm{MW} / \mathrm{m}^{2}\right)$ & 10 & 20 \\
\hline
\end{tabular}

Table 1: Model System and Flow Conditions

Three separate models were developed for the solver to evaluate. Two models had twisted tapes, one with a TR of two and one 
with a TR of one while the third model had no tape insert. A total of 142 monoblocks line the channel with the first 58 monoblocks denoting the extent of the linear high heat flux lower vertical target with the remainder making up the curved upper vertical target. A cutaway showing the full model with the twisted tape throughout the channel is seen in Figure 2. The divertor is developed from specifications used during the divertor qualification programme to ensure the most accurate representation of the divertor. Detailed geometric parameters are found in the following reference [56]. Material properties for metals used in the simulation are found in the following reference [57].

\section{Boundary and Initial Conditions}

Heat flux is applied to the monoblocks of the LVT and UVT using a ramp function. This function increases the heat flux from zero to the maximum specified heat flux, in equal steps, over the first 2000 iterations allowing the flow to develop before boiling occurs. All other surfaces are considered adiabatic and no contact resistance is applied at solid/solid interfaces. Flow enters the domain through a velocity inlet at $\operatorname{Vin}=9 \mathrm{~m} / \mathrm{s}$ and $\operatorname{Tin}=373 \mathrm{~K}$ and exits through a pressure outlet. The flow domain is initialised using Vin and Tin at a reference pressure of Psys and zero initial vapour volume fraction.

\section{Computational Grid}

A grid independency study was performed where the final grid of roughly 1.8 million cells was selected with particular attention being paid to the near-wall regions to ensure $30 \leq y^{+} \leq 150$ for the all $\mathrm{y}+$ two-layer realizable $k-\varepsilon$ turbulence model. A polyhedral mesh is used to discretise the geometry with prism layers used to capture the boundary layer. Mesh dependency was assessed by monitoring maximum surface temperature of the final monoblock on the LVT, average vapour content of the channel and liquid velocity at the outlet. The mesh was steadily refined and was selected when the percentage change of the monitored values was within $5 \%$ of the subsequent refined mesh. Maximum surface temperature was within $1 \%$ of those obtained on the highly refined 5.8 million cell mesh.

\section{RESULTS AND DISCUSSION}

In this section the results of the CFD simulations of the divertor single-channel are presented. The divertor was simulated at both $10 \mathrm{MW} / \mathrm{m}^{2}$ and $20 \mathrm{MW} / \mathrm{m}^{2}$ as well as investigating the influence of the performance with and without tape as well as with increased twist ratio.

Results for Figures 5 and 6 are presented as crosssectional planes through the first and last monoblocks of the lower vertical target. The results are presented for the ITER configuration without modifications to validate the temperature distribution predictions throughout the divertor. Hirai et al. [55] performed testing on monoblocks with an armour thickness of $7.7 \mathrm{~mm}$ while this study uses an armour thickness of $8 \mathrm{~mm}$. However, the results at low heat flux are at most within $10 \%$ of experimental prediction and at high heat flux are within $5 \%$ of experimental prediction. When compared with the FEM model assuming a constant heat transfer coefficient for the divertor performance, the maximum surface temperatures are within 5\% while the minimum temperatures on the monoblocks are within $15 \%$ on average and $20 \%$ at maximum. These results are promising and serve as a good indication that the boiling model is capable of modelling ultra-high heat flux scenarios in the absence of void fraction data for validation. The average heat transfer coefficient is compared with that of the heat transfer coefficient for pipe with swirl tape used by Hirai et al. [55] in their finite element analysis. On average, the current simulation of the divertor predicted a heat transfer coefficient of $102.31 \mathrm{~kW} / \mathrm{m}^{2} \mathrm{~K}$ across both heat loads, which is in close agreement with the value of $100 \mathrm{~kW} / \mathrm{m}^{2} \mathrm{~K}$ used by the Hirai et al. [55]. Individually the heat transfer coefficients were within $15 \%$ of the expected performance of the divertor.

With confidence established in the capability of the model to predict the temperatures expected within the divertor, the next step is to evaluate the performance of the divertor with the tape removed and then by including a more twisted tape. Figures $7 \mathrm{a}$ and $7 \mathrm{~b}$ show the temperature distributions over the cross- 
sections of the first and last monoblocks with no tape included. It is clear that the removal of the tape has significantly degraded the cooling performance of the divertor. The loss of internal mixing after the removal of the tape prevents new fluid from circulating to the heated section of the wall, substantially reducing the boiling heat removal along the wall. Instead the bubbles are unable to leave the near-wall vicinity and allow cooler fluid to convect away the heat. Figure $7 \mathrm{~b}$ shows that the upper circumference of the channel is now over $700 \mathrm{~K}$ while with tape included only a fraction of the channel reached beyond saturation temperature. Running the model at $20 \mathrm{MW} / \mathrm{m}^{2}$ with no tape resulted in a complete breakdown in the cooling process due to reaching critical heat flux and subsequent burnout of the coolant.

The effects can be better seen by comparing the 3D isometric views of the models and investigating the surface temperatures on the monoblock roofs. It is clear from Figure 8a that the temperature concentration towards the end of the LVT is a result of the aforementioned diminished cooling capacity. Temperatures are now more than $17 \%$ higher in the final monoblocks. Temperatures in the UVT are far lower given their reduced heat flux and that the fully developed central fluid core is now able to make contact with the upper portion of the $\mathrm{CuCrZr}$ pipe. This is clearer from Figure 9a which presents the vapour concentration throughout the centre of the divertor channel. The vapour layer is now pierced by the high velocity subcooled core and the lighter bubbles are easily displaced to the bottom of the channel in the UVT. Figure $9 \mathrm{~b}$ reveals that the inclusion of the twisted tape allows the divertor to maintain a very consistent surface temperature along each of the monoblocks on both the UVT and LVT with significant reduction in vapour generation. The inclusion of the tape has a drastic impact on the vapour generation within the channel resulting in the prediction of almost fully single-phase cooling within the divertor. The average volume fraction dropped by over 15 times to almost zero vapour generation. Each material within the system has its own operating limit and for the $\mathrm{CuCrZr}$ pipe this limit is $773 \mathrm{~K}$ [58].
It is evident that the $10 \mathrm{MW} / \mathrm{m}^{2}$ load is too high for the straight pipe with no tape to withstand as wall temperatures exceed the temperature limit. The effects of the twisted tape allow the divertor to perform at both expected operating heat fluxes without exceeding the safety limits imposed. It is predicted that including the twisted tape increases the heat transfer coefficient of the system by almost $45 \%$.

The effects of the twisted tape on maintaining the highly subcooled nature of the flow can be seen in Figures 10a and 10b which show liquid subcooling. The mixing capability of the tape is far more visible with the solver predicting that the bulk of the flow remains almost $100 \mathrm{~K}$ below the saturation temperature, a value which is expected from the design analysis as presented by Koski and Watson [21].

Wall temperature data is taken from the top of the LVT channel and is compared for all three divertor configurations in Figure 11a. The poor performance of the divertor without twisted tape is clear as $0.5 \mathrm{~m}$ along the channel, fluid saturation temperature is exceeded due to fluid burnout. This indicates a catastrophic failure of the channel wall will occur. The introduction of the twisted tapes ensures that the wall remains at saturation temperature and well below the thermal limit. There is a small but noticeable impact on the performance when using the TR1 tape as it delays boiling to $0.1 \mathrm{~m}$ along the channel while the TR2 configuration appears to have boiling directly beneath the first monoblock. This difference may be attributed to the increased single-phase performance of the more highly twisted tape. Figure $11 \mathrm{~b}$ reveals that even with the heat flux doubled, the wall temperature remains around saturation temperature and well below the thermal limits of the wall.

Evaluation of the performance with the twist ratio of one revealed that there is little to be gained by using the more twisted tape. By increasing the twist ratio there was a predicted $12.5 \%$ drop in the average vapour fraction. Correspondingly, single-phase wall heat flux saw a $9 \%$ increase, and this can be attributed to the increased flow length, increased fluid velocity and the enhancement of the swirling flow mixing. Given the 
increased vapour generation, the lower twist ratio resulted in increased bubble induced quenching heat flux and evaporative heat flux.

\section{CONCLUSIONS}

The two-fluid numerical model applied in this paper was found to predict the temperature profiles within the divertor to a high degree of accuracy. The surface temperatures at both $10 \mathrm{MW} / \mathrm{m}^{2}$ and $20 \mathrm{MW} / \mathrm{m}^{2}$ were accurately predicted to match the experimental data provided by the ITER Organisation. Some results, however, are less satisfactory with there being a noticeable over-prediction in the vapour volume fraction which has a direct impact on the prediction accuracy of the wall heat fluxes. The model may be further improved by the introduction of more accurate bubble departure modelling as well as better turbulent dispersion modelling coupled with bubble coalescence and breakup models. These are components of the computational model which have a direct and critical impact on the heat transfer at the wall. Difficulties in modelling these quantities exist in plain pipes without the added complexities of the twisted tape. Currently the existing correlations all originate in pipes that do not have such convoluted flow conditions. This is an area which certainly requires further study. As this model is not truly mechanistic it is possible to spend more time further tuning these empirical correlations to the ITER divertor system. In particular, an S- $\gamma$ model could be utilised for modelling bubble departure, breakup and coalescence while turbulence modelling should be conducted using a Reynolds stress model.

The key physical findings of this study can be summarised as follows:

- The model is found to predict the monoblock surface temperatures within the fusion reactor conditions to within $5 \%$ of the experimental data.

- The inclusion of twisted tape is a necessity as its cooling performance enhancement extends the operational capability of the divertor to $10 \mathrm{MW} / \mathrm{m}^{2}$ and $20 \mathrm{MW} / \mathrm{m}^{2}$.
- The inclusion of the twisted tape increased the heat transfer coefficient of the system by almost $45 \%$ and reduced material temperatures to comply with the operating limits.

- The analyses conducted predicted a highly subcooled liquid core and heat transfer coefficient that were in-line with design requirements and analysis produced for the divertor.

- The presence of a tape with a twist ratio of two is more than adequate for the heat transfer performance as any more twisting has a negligible impact on the thermal performance.

\section{ACKNOWLEDGEMENT}

The authors gratefully acknowledge the financial support provided by Mott MacDonald Ltd.

\section{REFERENCES}

[1] Wong, K. V., and Dia, S., 2017, "Developments in Nuclear Power and Radioactive Waste Management," J. Energy Resour. Technol., 139(6).

[2] Energy Information Administration, U., 2019, International Energy Outlook 2019.

[3] Energy Agency, I., 2015, Key World Energy Statistics 2015.

[4] "The Most Expensive Nuclear Energy Projects around the World - Future Power Technology | Special Issue | November 2018" [Online]. Available: https://power.nridigital.com/power_technology_nov18_ special/the_most_expensive_nuclear_energy_projects_ around_the_world. [Accessed: 03-Jan-2020].

[5] "What Is ITER?" [Online]. Available: https://www.iter.org/proj/inafewlines. [Accessed: 03Jan-2020].

[6] Claessens, M., 2020, ITER: The Giant Fusion Reactor.

[7] "External Heating Systems" [Online]. Available: https://www.iter.org/mach/Heating. [Accessed: 03-Jan- 
2020].

"Machine"

[Online].

Available:

https://www.iter.org/mach. [Accessed: 06-Jan-2020].

[9] Dobran, F., 2012, "Fusion Energy Conversion in Magnetically Confined Plasma Reactors," Prog. Nucl. Energy, 60, pp. 89-116.

[10] Ishii, M., and Hibiki, T., 2011, Thermo-Fluid Dynamics of Two-Phase Flow (Second Edition), Springer New York.

[11] Mohanty, R. L., and Das, M. K., 2017, "A Critical Review on Bubble Dynamics Parameters Influencing Boiling Heat Transfer," Renew. Sustain. Energy Rev., 78, pp. 466-494.

[12] Hirai, T., Escourbiac, F., Carpentier-Chouchana, S., Fedosov, A., Ferrand, L., Jokinen, T., Komarov, V., Kukushkin, A., Merola, M., Mitteau, R., Pitts, R. A., Shu, W., Sugihara, M., Riccardi, B., Suzuki, S., and Villari, R., 2013, "ITER Tungsten Divertor Design Development and Qualification Program," Fusion Eng. Des., 88(9-10), pp. 1798-1801.

[13] Natalizio, A., Collen, J., and Vieider, G., 1997, “Cooling System Design Options for a Fusion Reactor 1," J. Fusion Energy, 16(12), pp. 0-4.

[14] Brezinsek, S., 2015, "Plasma-Surface Interaction in the $\mathrm{Be} / \mathrm{W}$ Environment: Conclusions Drawn from the JETILW for ITER , JET-EFDA Contributors."

[15] Gunn, J. P., Carpentier-Chouchana, S., Dejarnac, R., Escourbiac, F., Hirai, T., Komm, M., Kukushkin, A., Panayotis, S., and Pitts, R. A., 2017, "Ion Orbit Modelling of ELM Heat Loads on ITER Divertor Vertical Targets," Nucl. Mater. Energy, 12, pp. 75-83.

[16] Raffray, A. R., Schlosser, J., Akiba, M., Araki, M., Chiocchio, S., Driemeyer, D., Escourbiac, F., Grigoriev, S., Merola, M., Tivey, R., Vieider, G., and Youchison, D., 1999, "Critical Heat Flux Analysis and R\&amp;D for the Design of the ITER Divertor,” Fusion Eng. Des., 45(4), pp. $377-407$.
[17] Zagórski, R., Pericoli, V., and Telesca, G., 2011, "Integrated Modeling of ITER Scenarious with Carbon and Tungsten Walls."

[18] Krepper, E., Končar, B., and Egorov, Y., 2007, "CFD Modelling of Subcooled Boiling-Concept, Validation and Application to Fuel Assembly Design," Nucl. Eng. Des., 237(7), pp. 716-731

[19] Langari, M., Yang, Z., Dunne, J. F., Jafari, S., Pirault, J. P., Long, C. A., and Thalackottore Jose, J., 2018, "Conjugate Heat Transfer Predictions for Subcooled Boiling Flow in a Horizontal Channel Using a Volumeof-Fluid Framework,” J. Heat Transfer, 140(10), pp. 16.

[20] Colombo, M., and Fairweather, M., 2016, “Accuracy of Eulerian-Eulerian, Two-Fluid CFD Boiling Models of Subcooled Boiling Flows,” Int. J. Heat Mass Transf., 103, pp. 28-44.

[21] Koski, J. A. Watson, R. D., “THERMAL-HYDRAULIC DESIGN ISSUES AND ANALYSIS FOR THE ITER DIVERTOR.”

[22] Collier, J. G., and Thome, J. R., 1994, Convective Boiling and Condensation.

[23] Sanna, A., Hutter, C., Kenning, D. B. R., Karayiannis, T. G., Sefiane, K., and Nelson, R. A., 2014, "Numerical Investigation of Nucleate Boiling Heat Transfer on Thin Substrates,” Int. J. Heat Mass Transf., 76, pp. 45-64.

[24] Chen, D., Pan, L. M., and Ren, S., 2012, "Prediction of Bubble Detachment Diameter in Flow Boiling Based on Force Analysis," Nucl. Eng. Des., 243, pp. 263-271.

"A Method of Correlating Heat Transfer Data for Surface Boiling of Liquids" [Online]. Available: https://dspace.mit.edu/handle/1721.1/61431. [Accessed: 14-Dec-2019].

[26] Banerjee, S., and Agarwal, R. K., 2016, “An Eulerian Approach to Computational Fluid Dynamics Simulation of a Chemical-Looping Combustion Reactor With Chemical Reactions," J. Energy Resour. Technol., 
138(4), pp. 1-9.

[27] Colombo, M., and Fairweather, M., 2016, “Accuracy of Eulerian-Eulerian, Two-Fluid CFD Boiling Models of Subcooled Boiling Flows,” Int. J. Heat Mass Transf., 103, pp. 28-44.

[28] Ostermeier, P., Vandersickel, A., Gleis, S., and Spliethoff, H., 2019, "Numerical Approaches for Modeling Gas-Solid Fluidized Bed Reactors: Comparison of Models and Application to Different Technical Problems,” J. Energy Resour. Technol. Trans. ASME, 141(7), pp. 1-10.

[29] Yang, M., Banerjee, S., and Agarwal, R. K., 2018, "Transient Cold Flow Simulation of Fast Fluidized Bed Fuel Reactors for Chemical-Looping Combustion,” J. Energy Resour. Technol., 140(11).

[30] Drew, D. A., and Passman, S. L., 1999, Theory of Multicomponent Fluids, Springer New York, New York, NY.

[31] Podowski, M. Z., and Podowski, R. M., 2009, "Mechanistic Multidimensional Modeling of Forced Convection Boiling Heat Transfer," Sci. Technol. Nucl. Install., 2009(August).

[32] Hoang, N. H., Chu, I. C., Euh, D. J., and Song, C. H., 2016, "A Mechanistic Model for Predicting the Maximum Diameter of Vapor Bubbles in a Subcooled Boiling Flow,” Int. J. Heat Mass Transf., 94, pp. 174179.

[33] Bartolomei, G., and Chanturia, V. M., 1967, "Experimental Study of True Void Fraction When Boiling Subcooled Water in Vertical Tubes," Teploenergetika, 14(2), pp. 123-128.

[34] Bartolomei G.G. et al., 1982, "An Experimental Investigation of True Volumetric Vapor Content with Subcooled Boiling in Tubes," Teploenergetika, 29(3), pp. 132-135.

[35] "M. Lemmert and J. M. Chawla, 'Influence of Flow Velocity on Surface Boiling Heat Transfer Coefficient,' in Heat Transfer in Boiling, E. Hahne and U. Grigull, Eds., Pp. 237-247, Academic Press and Hemisphere, 1977. - Open Access Library" [Online]. Available: http://www.oalib.com/references/14279200. [Accessed: 15-Dec-2019].

[36] Hibiki, T., and Ishii, M., 2003, "Active Nucleation Site Density in Boiling Systems," Int. J. Heat Mass Transf., 46(14), pp. 2587-2601.

[37] Cole, R., 1960, “A Photographic Study of Pool Boiling in the Region of the Critical Heat Flux," AIChE J., 6(4), pp. 533-538.

[38] Tolubinsky, V. I., and Kostanchuk, D. M., 2019, "VAPOUR BUBBLES GROWTH RATE AND HEAT TRANSFER INTENSITY AT SUBCOOLED WATER BOILING,” Begell House, pp. 1-11.

[39] Kocamustafaogullari, G., 1983, "Pressure Dependence of Bubble Departure Diameter for Water," Int. Commun. Heat Mass Transf., 10(6), pp. 501-509.

[40] Yun, B. J., Splawski, A., Lo, S., and Song, C. H., 2012, "Prediction of a Subcooled Boiling Flow with Advanced Two-Phase Flow Models," Nucl. Eng. Des., 253, pp. 351-359.

[41] Končar, B., and Tiselj, I., 2010, "Influence of Near-Wall Modelling on Boiling Flow Simulation," Nucl. Eng. Des., 240(2), pp. 275-283.

[42] Bergles, A. E., 2003, "High-Flux Processes through Enhanced Heat Transfer," 5th Int. Conf. Boil. Heat Transf., pp. 1-13.

[43] Manglik, R. M., and Bergles, A. E., 2003, "Swirl Flow Heat Transfer and Pressure Drop with Twisted-Tape Inserts," Adv. Heat Transf., 36(C), pp. 183-266.

[44] Giniyatullin, A. A., and Tarasevich, S. E., 2013, "CFD Modelling of Subcooled Boiling in Tubes with Twisted Tape Insert," American Society of Mechanical Engineers, Fluids Engineering Division (Publication) FEDSM.

[45] Liu, P., Peng, X. B., Song, Y. T., and Mao, X., 2017 , 
"Subcooled Water Flow Boiling Heat Transfer in Screw Cooling Tubes under One-Sided Heating Conditions," Appl. Therm. Eng., 113, pp. 621-631.

[46] Siemens, 2019, "STAR-CCM+ V13.02.013."

[47] Podowski, M. Z., Antal, S. P., Tselishcheva, E. A., and Wierzbicki, B. Z., 2007, DEVELOPMENT OF MECHANISTIC MODELS OF TWO-PHASE FLOWS FOR THE NPHASE CODE.

[48] Shih, T. H., Liou, W. W., Shabbir, A., Yang, Z., and Zhu, J., 1995, “A New K-E\{lunate\} Eddy Viscosity Model for High Reynolds Number Turbulent Flows," Comput. Fluids, 24(3), pp. 227-238.

[49] Kurul, N., and Podowski, M. Z., 2019, "MULTIDIMENSIONAL EFFECTS IN FORCED CONVECTION SUBCOOLED BOILING," Begell House, pp. 21-26.

[50] Del Valle, V. H., and Kenning, D. B. R., 1985, "Subcooled Flow Boiling at High Heat Flux," Int. J. Heat Mass Transf., 28(10), pp. 1907-1920.

[51] Hoang, N. H., Chu, I. C., Euh, D. J., and Song, C. H., ON THE APPLICATION OF WALL BOILING MODELS TO PREDICTION OF SUBCOOLED FLOW BOILING USING EAGLE CODE.

[52] Cole, R., 1960, “A Photographic Study of Pool Boiling in the Region of the Critical Heat Flux," AIChE J., 6(4), pp. 533-538.

[53] Ranz, W.E. Marshall, W. R., 1952, "Evaporation from Drops--Part I and II,” Chem. Eng. Prog., 48(3), p. 141.

[54] Tomiyama, A., Kataoka, I., Zun, I., and Sakaguchi, T., 1998, "Drag Coefficients of Single Bubbles under Normal and Micro Gravity Conditions," JSME Int. Journal, Ser. B Fluids Therm. Eng., 41(2), pp. 472-479.

[55] Hirai, T., Panayotis, S., Barabash, V., Amzallag, C., Escourbiac, F., Durocher, A., Merola, M., Linke, J., Loewenhoff, T., Pintsuk, G., Wirtz, M., and Uytdenhouwen, I., 2016, "Use of Tungsten Material for the ITER Divertor," Nucl. Mater. Energy, 9, pp. 616-
622.

[56] Merola, M., 2013, MIIFED Conference-Forum on The WEST Project-4 December 2013 The ITER Divertor.

[57] Hancock, D., Homfray, D., Porton, M., Todd, I., and Wynne, B., Refractory Metals as Structural Materials for Fusion High Heat Flux Components.

[58] Pintsuk, G., Blumm, J., Hohenauer, W., Hula, R. C., Koppitz, T., Lindig, S., Pitzer, D., Rohde, M., Schoderböck, P., Schubert, T., Tietz, F., and Wouters, O., Inter-Laboratory Test on Thermophysical Properties of the ITER Grade Heat Sink Material Copper-ChromiumZirconium. 


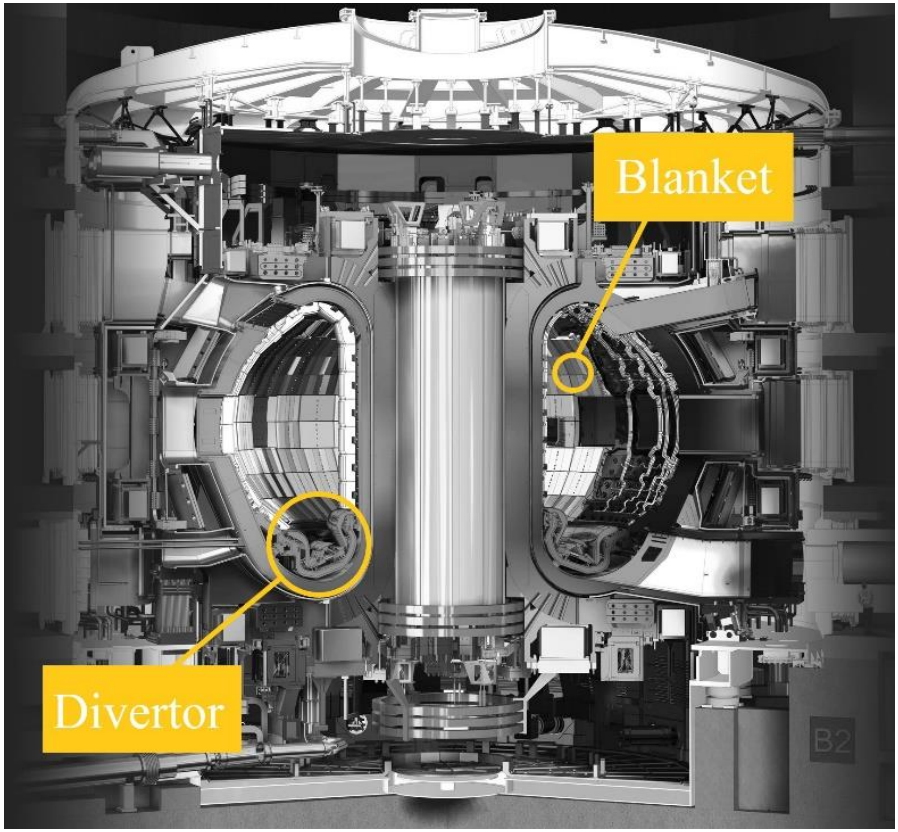

Figure 1: Cutaway render of the ITER tokamak complex highlighting the blanket and the divertor

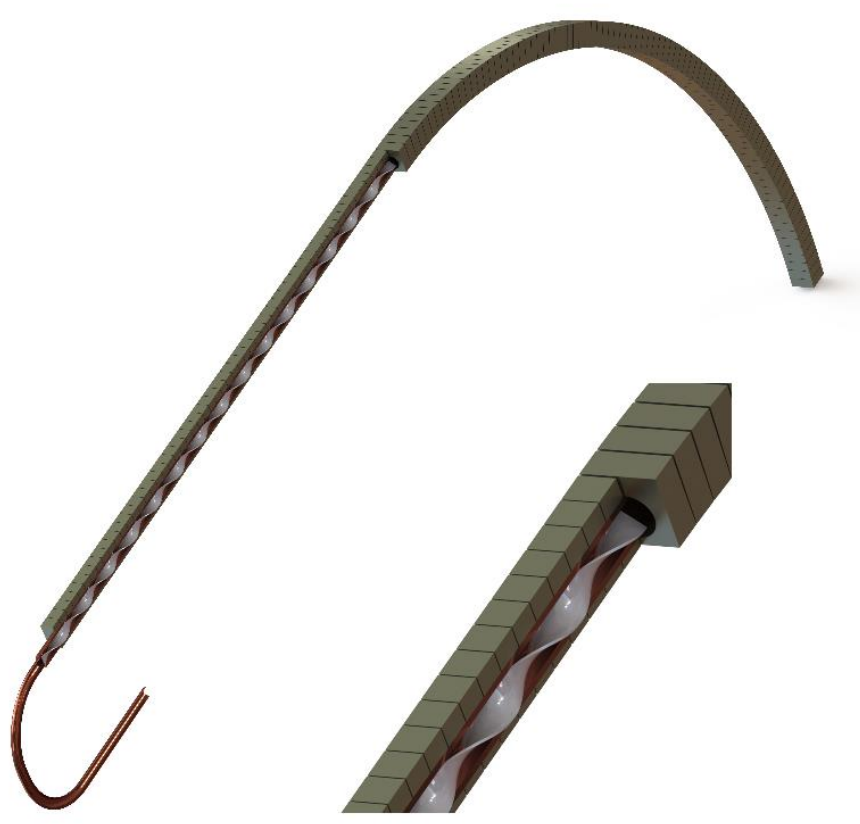

Figure 2: Cutaway of the divertor model revealing the full extent of the twisted tape with close-up showing the end of the LVT

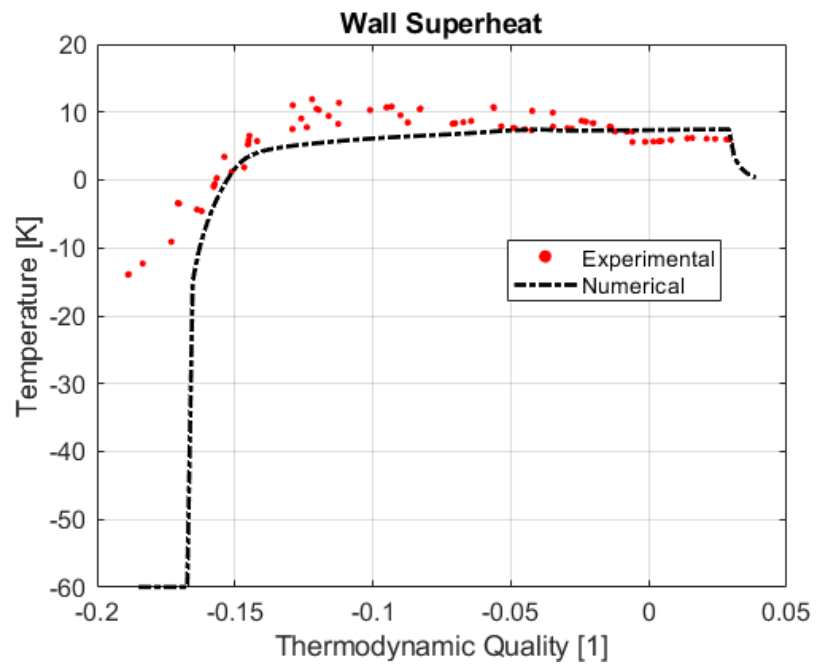

(a)

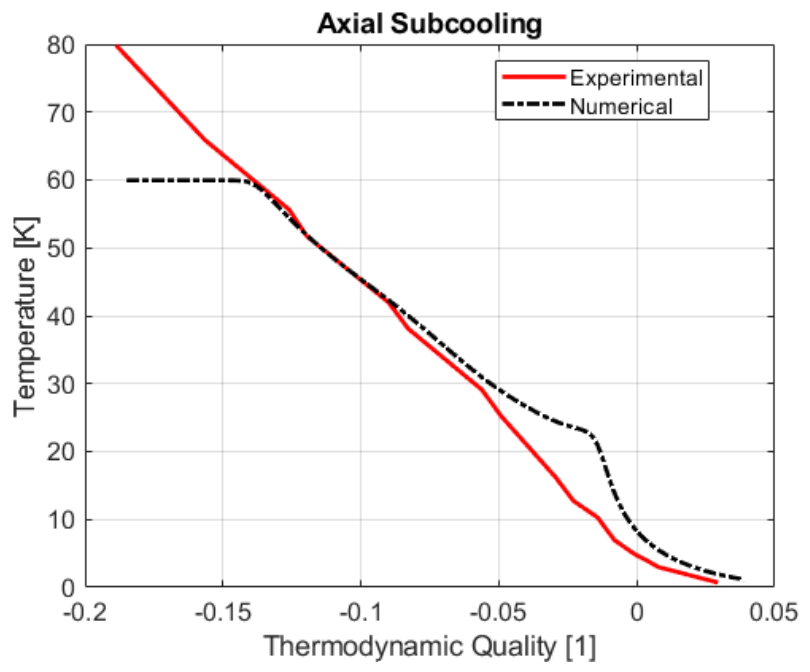

(b)

Figure 3: Boiling model temperature validation comparison with Bartolomei experimental data a) vvall superheat along the heated length in the channel b) Axial subcooling showing temperature comparisons at the centre of the heated length 


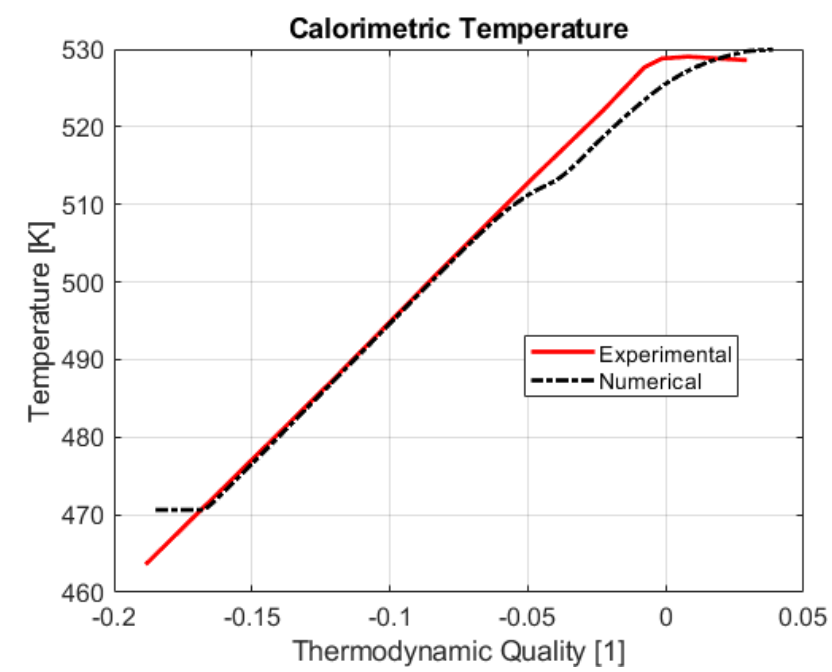

(a)

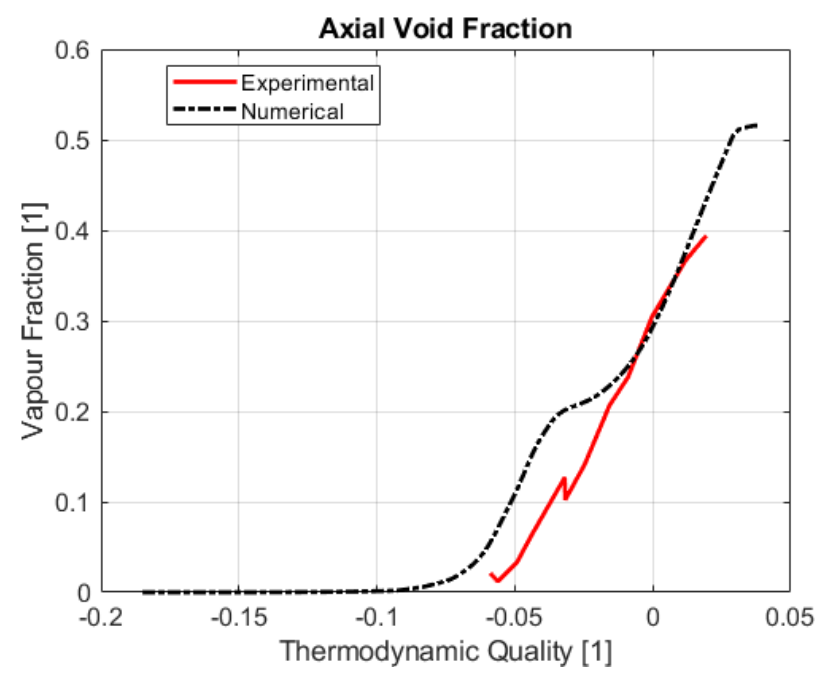

(b)

Figure 4: Boiling model validation a) Comparisons of bulk flow calorimetric temperature for CFD and Bartolomei b) Comparison of axial void fraction between CFD and experimental data
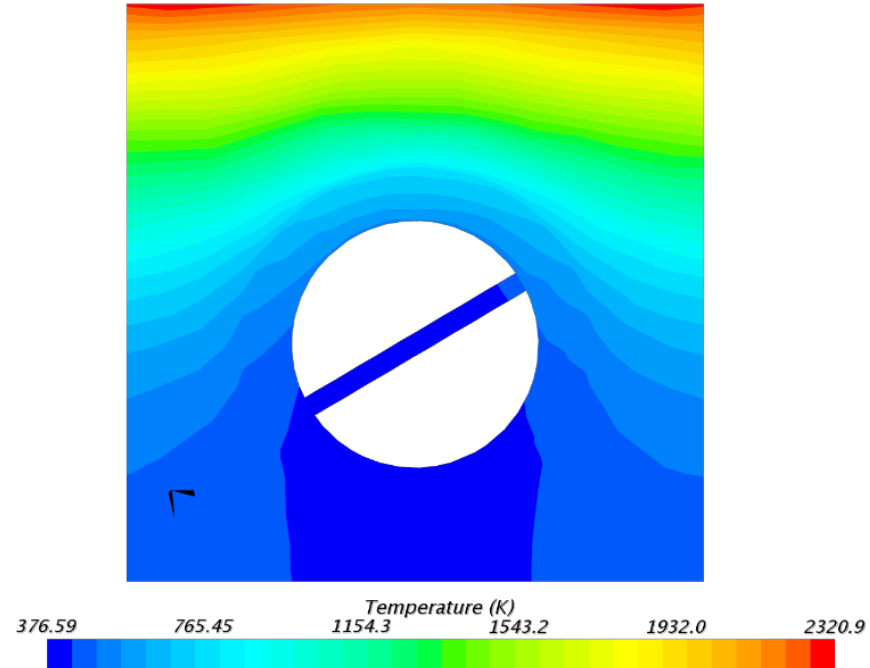

(a)
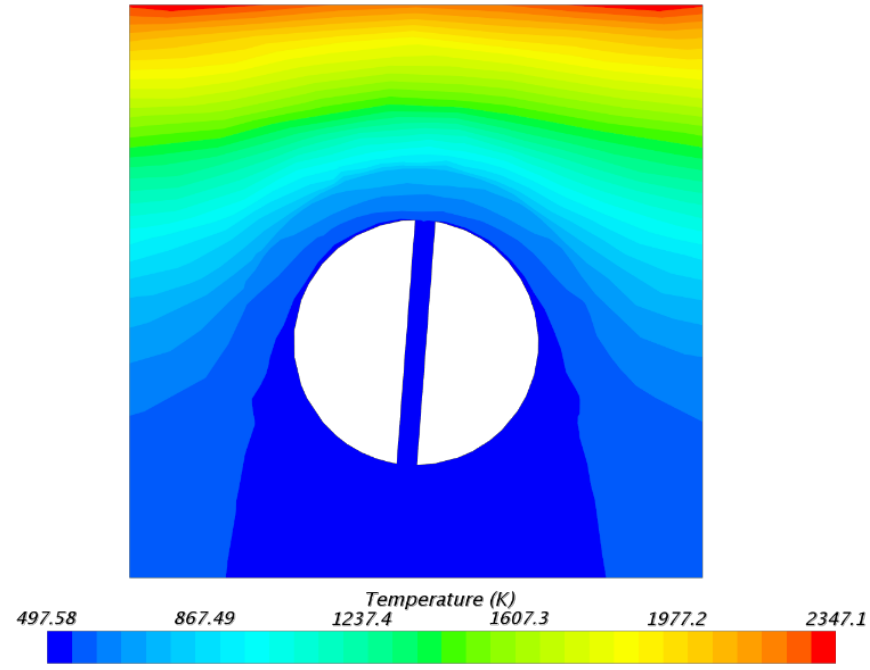

(b)

Figure 5: Monoblock temperature distributions at $20 \mathrm{MW} / \mathrm{m}^{2}$ heat flux and twist ratio of two a) first monoblock of LVT b) final monoblock of the UVT 

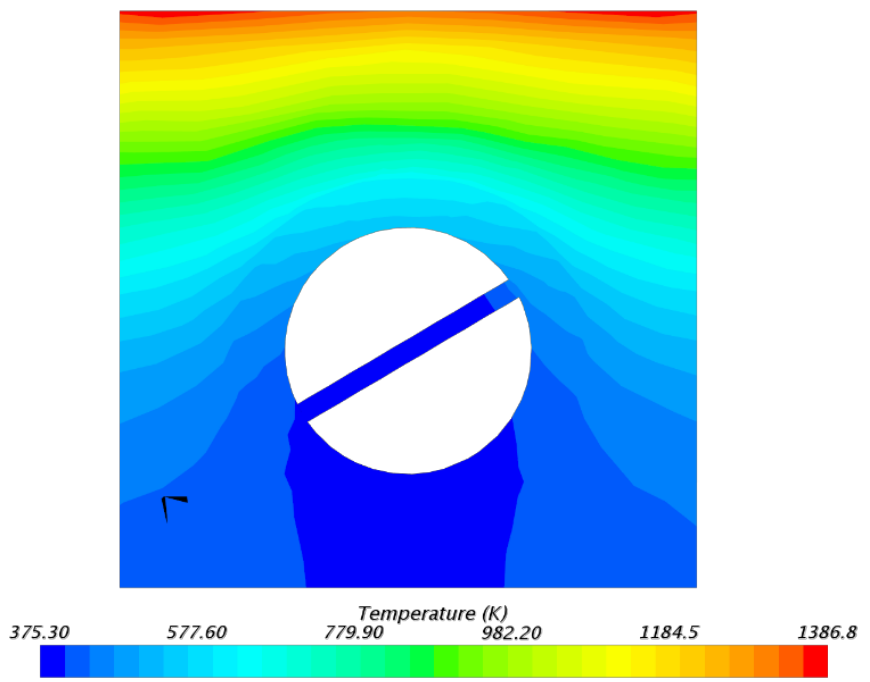

(a)

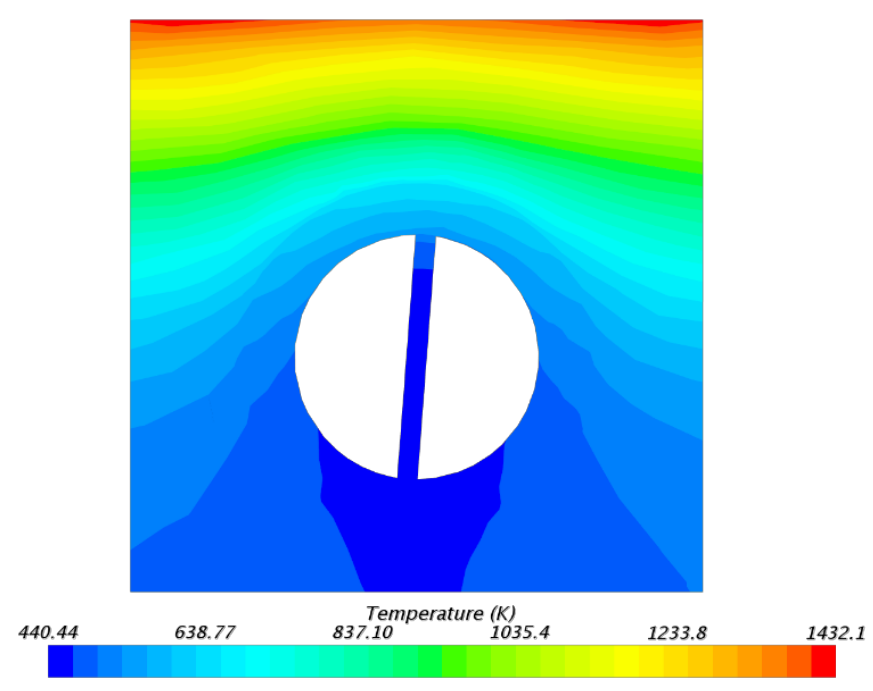

(b)

Figure 6: Monoblock temperature distributions at $10 \mathrm{MW} / \mathrm{m}^{2}$ heat flux and twist ratio of two a) first monoblock of LVT b) final monoblock of the UVT

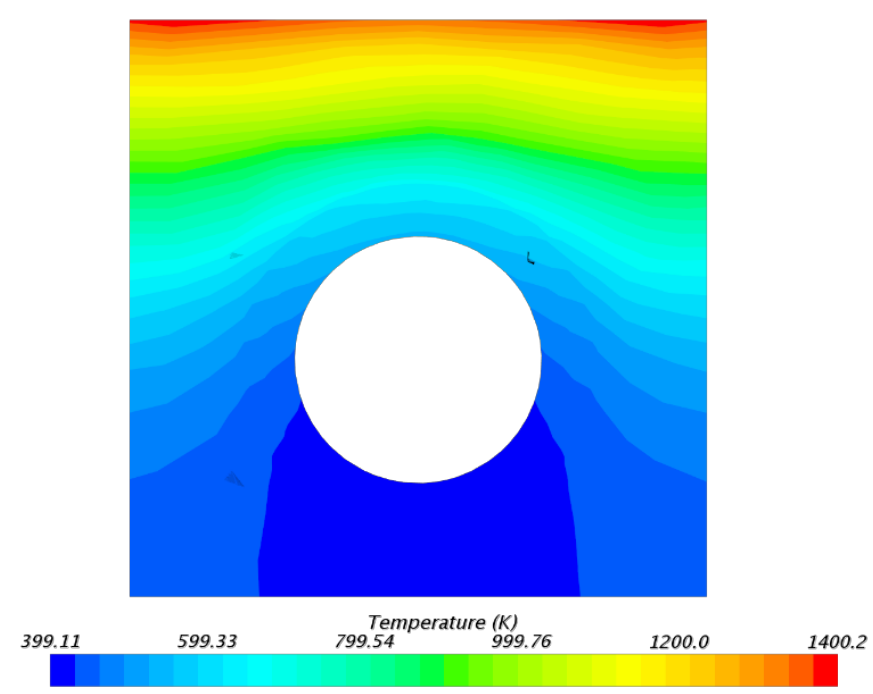

(a)

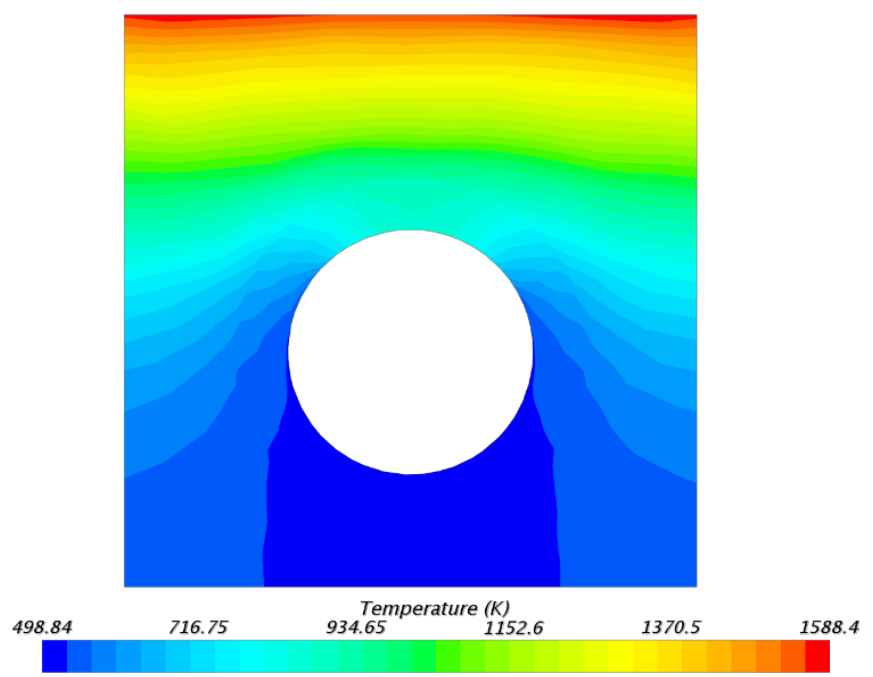

(b)

Figure 7: Monoblock temperature distributions at $10 \mathrm{MW} / \mathrm{m}^{2}$ heat flux and twisted tape removed a) first monoblock of LVT b) final monoblock of the LVT 


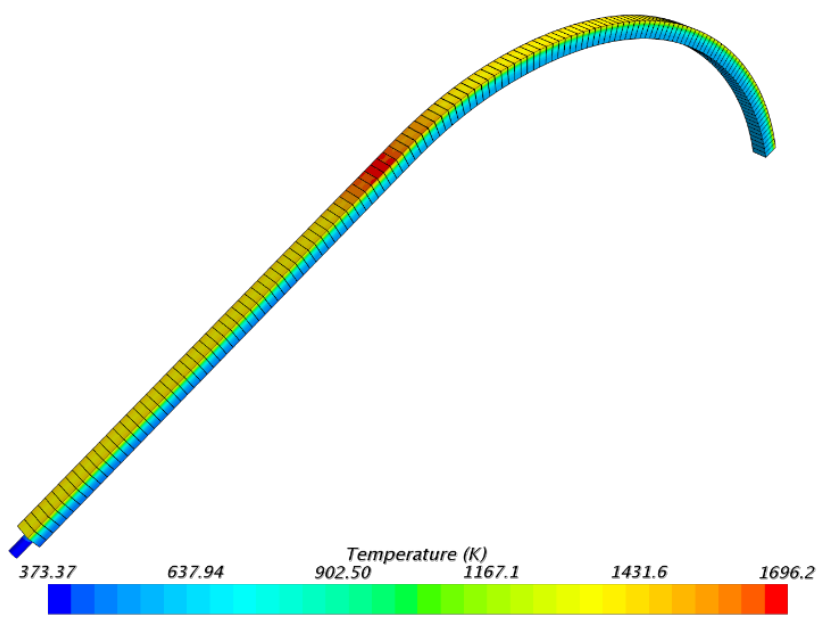

(a)

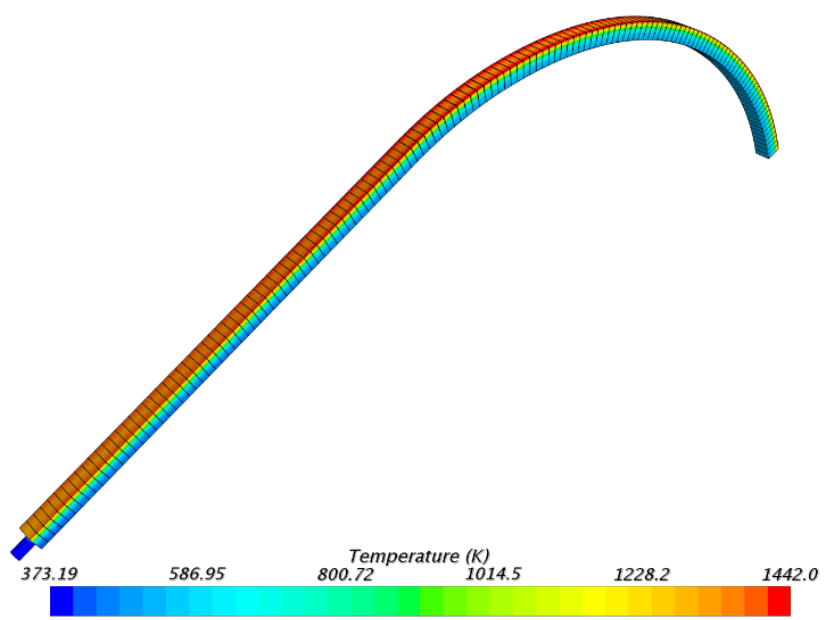

(b)

Figure 8: Isometric view of the surface temperatures for the full divertor channel a) Single-channel with tape removed b) Single-channel with tape with twist ratio of two included

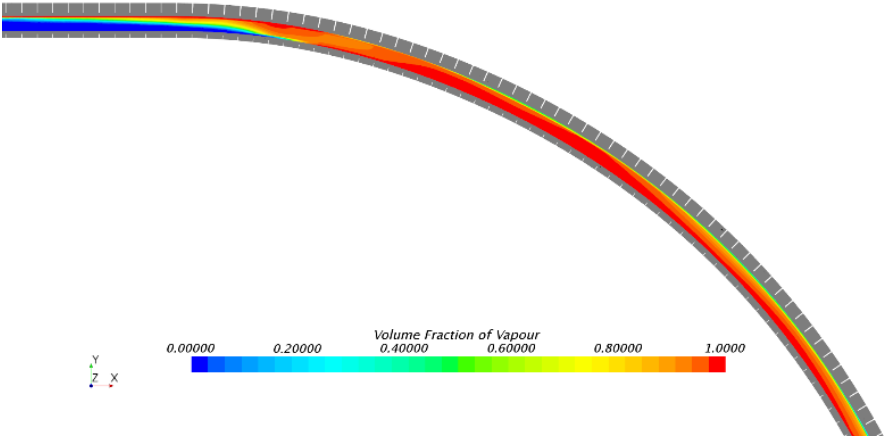

(a)

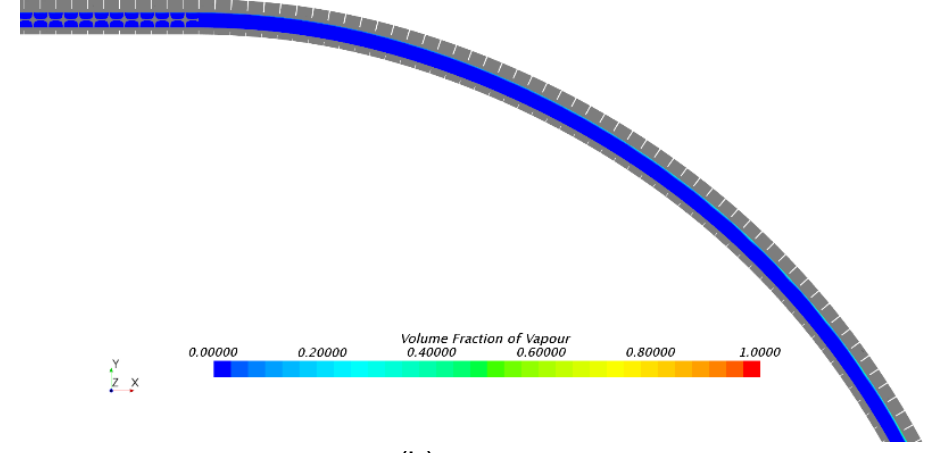

(b)

Figure 9: Longitudinal cross-section of upper divertor presenting the vapour volume fraction a) divertor at $10 \mathrm{MW} / \mathrm{m}^{2}$ with tape removed b) divertor at $10 \mathrm{MW} / \mathrm{m}^{2}$ with tape of twist ratio of one included 


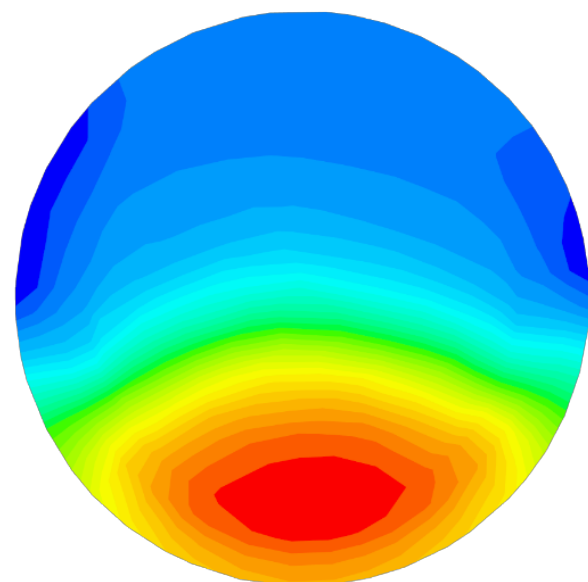

0.00000 16.224 32.448 64.896 81.119

(a)

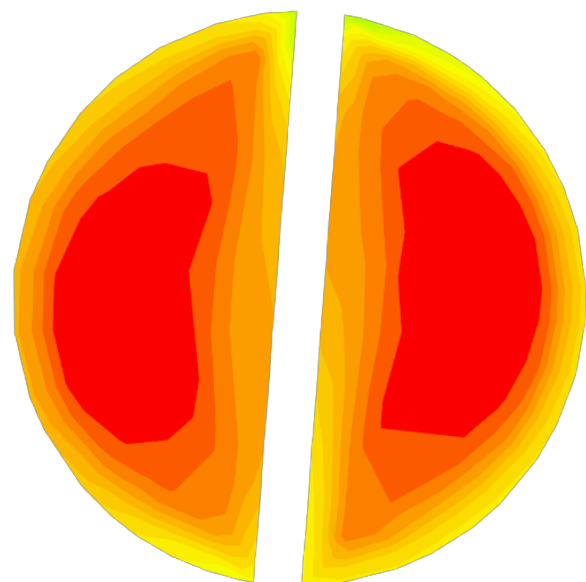

0.00000 19.682 LiquidSubcooling 78.729 98.411

(b)

Figure 10: Liquid subcooling at the final monoblock under a heat flux of $10 \mathrm{MW} / \mathrm{m}^{2}$ a) With tape removed b) With tape of twist ratio of two

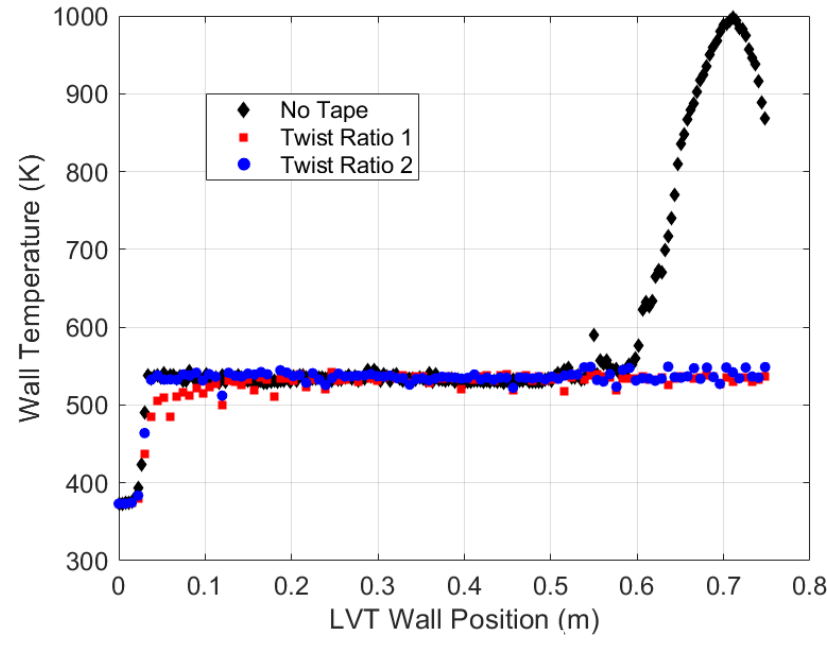

(a)

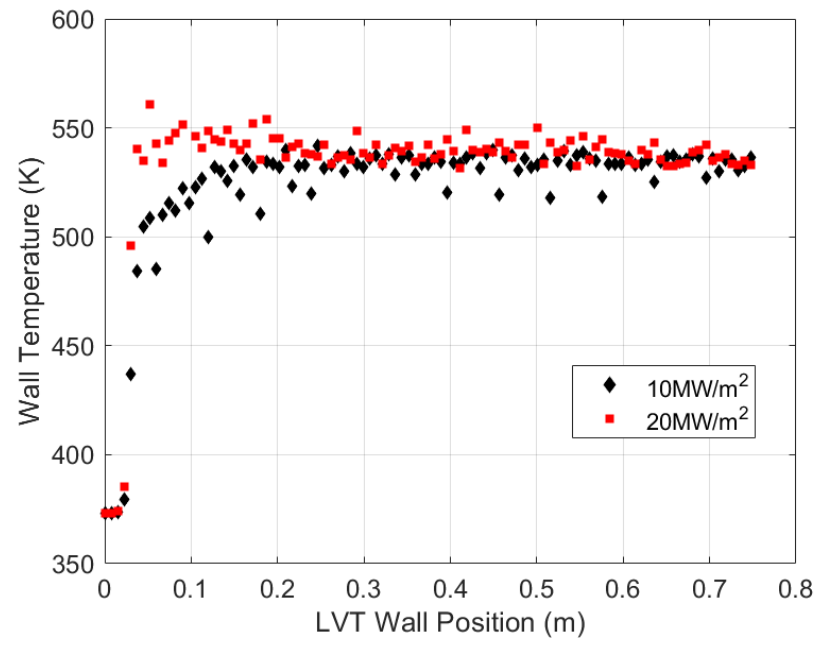

(b)

Figure 11: Comparison of wall temperature along the top of the LVT coolant channel in different configurations a) Divertor under $10 \mathrm{MW} / \mathrm{m}^{2}$ with no tape, tape of twist ratio one and tape of twist ratio two b) Divertor under $10 \mathrm{MW} / \mathrm{m}^{2}$ and $20 \mathrm{MW} / \mathrm{m}^{2}$ load with twist ratio of one 